\title{
ALTERNATIVAS E ESTRATÉGIAS DE AUTOCUIDADO EM SAÚDE MENTAL: RELATO DE EXPERIÊNCIA DE UM PROJETO DE EXTENSÃO
}

\author{
Bruna Araújo de Sá, Universidade Federal de Campina Grande (UFCG) \\ brunnadesaa@gmail.com \\ Daniela Cristina Pereira Ramos, Universidade Federal de Campina Grande (UFCG) \\ dannielacristinna@gmail.com \\ Sofia Dionizio Santos, Universidade Federal de Campina Grande (UFCG) \\ psycosofya@hotmail.com
}

\begin{abstract}
RESUMO
A discussão aqui empreendida é oriunda da vivência no Projeto "Auto-organização de mulheres e saúde", desenvolvido na cidade de Cajazeiras-PB, objetivando relatar as observações feitas durante o projeto numa perspectiva de desenvolver a saúde mental das mulheres envolvidas no mesmo. Para isso, necessitamos traçar estratégias baseadas em pesquisas bibliográficas, dinâmicas de grupo, bem como relatos dos indivíduos participantes das oficinas desenvolvidas. Com isso acreditamos ter propiciado à construção coletiva de conhecimento sobre a saúde mental, consequentemente permitindo a reflexão sobre a saúde mental das participantes do projeto, sendo este relevante para a transformação dos mesmos enquanto seres sociais.
\end{abstract}

PALAVRAS-CHAVE: Saúde mental; Saúde da mulher; Serviços de Saúde da Mulher.

\section{ALTERNATIVES AND SELF-CARE STRATEGIES IN MENTAL HEALTH: REPORT OF EXPERIENCE OF AN EXTENSION PROJECT}

\begin{abstract}
The discussion undertaken here arises from the experience in the project "Self-organization of women and health", developed in the city of Cajazeiras-PB. For this, we need to draw strategies based on bibliographical research, group dynamics, as well as reports of the individuals participating in the workshops developed. With this we believe to have propitiated the collective construction of knowledge about mental health, being this relevant for the transformation of them as social beings.
\end{abstract}

KEYWORDS: Mental health; Women's health; Women's Health Services.

Revista de Pesquisa Interdisciplinar, Cajazeiras, n. 2, suplementar, p. 660-671, set. de 2017. 


\title{
ALTERNATIVAS Y ESTRATEGIAS DE AUTOCUIDADO EN SALUD MENTAL: RELATO DE EXPERIENCIA DE UN PROYECTO DE EXTENSIÓN
}

\begin{abstract}
RESUMEN
La discusión aquí emprendida surge de la experiencia en el proyecto "Autoorganización de la mujer y la salud", desarrollado en la ciudad de Cajazeiras-PB. Para ello, es necesario elaborar estrategias basadas en investigaciones bibliográficas, dinámicas de grupo, así como informes de los participantes en los talleres desarrollados. Con esto creemos haber propiciado la construcción colectiva del conocimiento sobre la salud mental, siendo esto relevante para la transformación de ellos como seres sociales.
\end{abstract}

PALABRAS CLAVES: Salud mental; La salud de la mujer; Servicios de Salud de la Mujer.

INTRODUÇÃO

O presente trabalho parte das experiências vivenciadas no decorrer da participação do Projeto de Extensão intitulado “Auto-organização de Mulheres e Saúde”, vinculado ao Centro de Formação de Professores - CFP e à Unidade Acadêmica de Ciências da Vida - UACV, na Universidade Federal de Campina Grande, campus Cajazeiras, sob a coordenação da Professora Mestre Sofia Dionizio Santos, com a colaboração das extensionistas Bruna Araújo de Sá, (acadêmica do curso de Enfermagem), Joyce de Souza (acadêmica do curso de Enfermagem), Rosemary Torres do Nascimento (acadêmica do curso de Enfermagem), Daniela Cristina Pereira Ramos (acadêmica do curso de Pedagogia), e Vitória Feitosa de Souza (acadêmica do curso de História), tendo por objetivo promover a auto-organização das mulheres na luta por direitos, aproximando universidade e comunidade.

Durante a vigência de 2016 o projeto promoveu reuniões e desenvolveu ações junto às mulheres da comunidade do bairro Casas Populares na cidade de Cajazeiras - PB, bairro em que se localiza o CFP. Esses encontros ocorreram na escola na Escola Municipal Cecília 
Estolano, localizada também no bairro Casas Populares na cidade de Cajazeiras - PB, onde eram discutidos com as mulheres uma diversidade de temas relacionados à saúde integral da mulher. Em consequência do seu bom andamento, esse trabalho mantém sua continuidade no ano de 2017.

A discussão aqui proposta, portanto, parte de um relato de experiência em torno das oficinas promovidas pelo projeto no ano de 2016, em favor da promoção da saúde mental, com a participação das mulheres no Bairro Casas Populares na zona Norte de Cajazeiras.

Partindo de uma definição geral, a Organização Mundial da Saúde (OMS, 2002) conceitua saúde mental como um termo que descreve o equilíbrio emocional de um indivíduo que busca qualidade de vida, estando bem consigo e com os outros, sabendo lidar com suas emoções. Nos últimos anos, a saúde da mulher tem sido compreendida como um dos seus direitos e, como foco deste trabalho, destacaremos a saúde mental.

O Programa de Assistência Integral à Saúde da Mulher (PAISM, 2011) indica que a violência de gênero provoca uma elevada ocorrência de problemas referentes à saúde física e mental da mulher, isto porque, a mesma, possui características sociais, econômicas e culturais diferentes. É no espaço familiar que ocorre a maioria das agressões à mulher em que, o patriarcado e a dominação masculina, são vistas de forma natural.

Retrata-se a violência doméstica contra a mulher por ela ocorrer dentro do lar, pelo seu parceiro e/ou entre quaisquer membros da família, que se caracterizam por diversas formas que podem ocorrer neste espaço.

Segundo o Artigo $7^{\circ}$ da "Lei Maria da Penha", a Lei n 11.340/2006, são formas de violência, tais como, violência física, violência sexual, negligência e, entre elas, a violência psicológica que pode ou visa trazer danos a estrutura emocional da mulher, a sua identidade, ao seu desenvolvimento pessoal com ameaças, humilhações, isolamento social, oprimindo e alienando-as.

Das violências citadas, na maioria dos casos, a psicológica é a mais difícil de ser reconhecida pela própria vitima, pois ela vem mascarada pelos ciúmes, controle, ironias e ofensas.

É considerada violação dos direitos humanos a violência contra as mulheres em que, acomete seu direito de expressar-se e de ser respeitada em sua integridade física, mental e social. 
Vemos que a violência física é, de longe, a mais frequente, presente em $48,7 \%$ dos atendimentos, com especial incidência nas etapas jovem e adulta da vida da mulher, quando chega a representar perto de $60 \%$ do total de atendimentos. Em segundo lugar, a violência psicológica, presente em $23,0 \%$ dos atendimentos em todas as etapas, principalmente da jovem em diante. Em terceiro lugar, a violência sexual, objeto de $11,9 \%$ dos atendimentos, com maior incidência entre as crianças até 11 anos de idade $(29,0 \%$ dos atendimentos) e as adolescentes (24,3\%) (WAISELFISZ, 2015, p.50).

Considerando a importante relevância social deste tema, já que é crescente o número entre a população, evidencia-se um problema de saúde pública e social além de ser uma grande violação dos direitos humanos, é necessário uma olhar holístico, interdisciplinar, para estas mulheres, visando combater este fenômeno proporcionando uma assistência mais adequada tanto no âmbito social, quanto na saúde das mulheres vitimizadas.

Uma vez que detectamos, em nossas análises de rodas de conversas e outras informações coletadas em parceria com o Centro de Defesa das Mulheres Márcia Barbosa CDM, que a realidade referente à zona norte de Cajazeiras centra-se no alto número de mulheres que vivenciaram algum tipo de violência, bem como uma realidade opressora e machista. De maneira que tornou-se e necessário a promoção de estratégias e de um trabalho de intervenção que pudesse contribuir para mudança dessa realidade.

O presente estudo teve como finalidade descrever a experiência desenvolvida no projeto "Auto-organização de Mulheres e Saúde", na vigência de maio de 2016 a dezembro do mesmo ano, com objetivo de promover à importância dos cuidados a saúde mental junto às mulheres, avaliando fatores associados ao tema e construindo espaços para promoção de discussões junto à comunidade.

\section{METODOLOGIA}

A proposta teórica- metodológica empreendida desse relato de experiência parte das subjetividades dos agentes envolvidos. Desse modo trata-se de um estudo descritivo de relato de experiência desenvolvido na atuação do projeto "Auto-organização de Mulheres e Saúde". 
Enquanto aporte teórico realizou-se levantamento bibliográfico baseada em pesquisas de cartilhas e em revistas no levantamento de artigos publicados entre os anos de 2013 a 2017.

Foram realizadas buscas de artigos, tendo como critérios de inclusão para seleção de amostra, artigos em língua portuguesa e com abordagem da temática. Para os artigos analisados a utilização ao critério de exclusão, retirou-se os artigos de língua estrangeira e artigos duplicados e que não se encaixaram na margem de anos de proposta pela pesquisa.

Realizaram-se as buscas na Biblioteca Virtual de Saúde - BVS, nas bases de dados Literatura Latino-Americana e do Caribe em Ciências da Saúde - LILACS; na base de dadas bibliográficas em Psicologia Periódicas Técnico-Ciêntificos e para a pesquisa utilizou-se os seguintes descritores: Saúde Mental; Saúde da Mulher; Serviços de Saúde da Mulher. Identificou-se 48 artigos, destes foram selecionados seis após a análise minuciosa a fim de atender o objetivo do estudo.

O projeto teve como procedimento a escolha do tema apartir de propostas elencadas pelas mulheres através de rodas de conversa, no sentido de despertar em todas aquelas que participavam da atuação o cuidado em si. Diante das propostas abordadas, o grupo achou pertinente acrescentar à temática "saúde mental", tendo em vista que a relação de gênero é característica. O conhecimento da realidade possibilita conversar com o intuito de aproximar mais as mulheres com as participantes do projeto.

As formas de mediação da promoção da saúde estão vinculadas às práticas educativas, principalmente no que se refere à saúde mental que requerem o desenvolvimento do autocuidado para a prevenção.

As práticas de Educação e Saúde numa proposta de construção compartilhada devem ser orientadas pela busca da interdisciplinaridade, da autonomia e da cidadania. Ou seja, práticas que privilegiem a interação comunicacional onde sujeitos detentores de saberes diferentes, apropriam-se destes, transformando-se e transformando-os. (ACIOLI, 2008, p.120)

Assim, tivemos o cuidado de pensar as estratégias de intervenção de forma dialógica. De modo que as mulheres fossem ouvidas e também mediassem a discussão. Esse tipo de 
abordagem envolve fatores pedagógicos e metodológicos sendo compatível com a lógica Freireana.

Neste sentido, a educação libertadora, problematizadora, já não pode ser o ato de depositar, ou de narrar, ou de transferir, ou de transmitir "conhecimentos" e valores aos educandos, meros pacientes, à maneira da educação "bancária", mas um ato cognoscente. (FREIRE, 1987p. 39)

Logo, ocorre à crítica ao modo tradicional de mera transmissão do conhecimento em que visa apenas depositar as informações aos educandos, a aprendizagem é construída em ambos agentes, não havendo a diferenciação de educandos e educados no que se refere à detenção do saber, todos são agentes construtores do conhecimento e foi essa concepção que partilhamos para nortear as práticas educativas estabelecidas no projeto.

Enquanto meio para promoção da dialogicidade dinâmicas escolhidas para abordagem foram "eu me sinto bem quando", "eu me sinto mal quando" identificando estratégias e soluções de problemas e a dinâmica do relaxamento no qual, a pessoa do grupo, podia se manifestar naquele momento. Foi de extrema importância para as mulheres, pois possibilitou a oportunidade da fala entre elas e as extensionistas do projeto para as novas demandas a serem trabalhadas.

Destaca-se ainda, a sugestão de tarefas como desenhos e lápis de pintura para os filhos das mulheres participantes, para que as mesmas não deixassem de participar por estarem comprometidas com a tarefa do cuidar.

As atuações foram desenvolvidas na Escola Cecília Estolano Meireles localizada no município de Cajazeiras/PB em parceria com o Centro de Defesa das Mulheres Marcia Barbosa - CDM, no turno noturno nos meses de maio a dezembro de 2016. Os grupos ocorriam quinzenalmente com o tempo de uma hora de duração, às vezes as atuações se estendiam de acordo com o interesse do grupo; a frequência do grupo entre os meses de maio a dezembro variou entre 15 a 22 mulheres por encontro.

\section{RESULTADOS}


A experiência construída na atividade

A experiência é tida em dois eixos, o primeiro aponta as contribuições para as mulheres e segundo, a valorização da aprendizagem para as extensionistas. As atividades começaram através das oportunidades em que foram colhidos os temas de interesse para serem debatidos nos encontros subsequentes, no intuito de estimular a participação das mesmas nas ações do projeto. Para isto, foram elaborados temas e dinâmicas interativas que abordavam conteúdo informativo.

Após as explanações do tema tratado, as mulheres tinham um tempo para realizar questionamentos, entre elas e extensionistas, a fim de sanar suas duvidas e contribuir com suas experiências e/ou de familiares já vividas. Para a realização das dinâmicas, utilizaram-se cartolinas, pinceis para quadros e lápis de cor para a promoção e maior interação entre as mulheres.

Desenvolver atividades com relação aos temas envolve diretamente a promoção e sensibilização das mulheres, para que elas possam participar de forma positiva no cuidar da sua saúde mental, através de comportamentos e hábitos que objetivem o seu bem estar (MEINHARDT; DA MAIA, 2015).

Nisto, foram feitas perguntas a elas tais como: O que vocês fazem para se sentir bem? O que fazem para cuidar da sua saúde mental? Você tem com quem conversar com quem brincar... Vocês vão a festas? Como lidam com esses fatores de estresse (os filhos e marido que se drogam/bebem que saem sem informar para onde vão). As dinâmicas proporcionam uma melhor convivência aos integrantes na reação interpessoal provocando uma maior aproximação das participantes e diminuição da timidez.

A abordagem dessas dinâmicas é caracterizada pela transmissão de conhecimentos e valores de modo que, não se refere apenas a um espaço limitado do que é dito, é também uma busca da realidade e fragilidade encontrada neste meio, mas que proporcione uma maior autonomia e troca de experiências. Através das situações explanadas em dinâmica, a troca de informações transmite de forma coletiva o processo de enfrentamento individual, que resulta em uma troca de saberes para ambas (DUARTE, 2011). 
Nesta perspectiva, entende-se que o espaço dado às mulheres configura-se como um instrumento apresentando um meio de interação com fortalecimento de ações e saberes com as pessoas envolvidas. Os relatos das mulheres participantes reforçam o quanto foi enriquecedora a participação no projeto, bem como os resultados bem sucedidos dessa experiência.

Obtivemos o relato positivo de várias mulheres na participação das oficinas dentre eles destacamos o depoimento de Maria de Fátima da Silva, 60 anos, reside na Rua Raimundo Leite Rolim Sobrinho, S/N - Casas Populares.

"Eu gostei de participar do Projeto, por que pude entender um pouco dos problemas das outras mulheres e falar um pouco dos meus. É bom ter alguém que nos ouça sem julgamento e compartilhar algumas das nossas realidades; participo do AA (alcoólicos anônimos) e graças a Deus nunca mais coloquei um copo de bebida na boca. Gostaria que continuassem com o projeto, pois se tornaram minhas amigas."

E o de Maria Diana Fernandes Pereira, 28 anos, reside na Rua Balduino Neto, bairro São José, N: 87.

"Eu também gostei de participar! Eu trabalho em casa, levo e busco meus filhos na escola e às vezes não tenho tanto tempo pra mim. Com vocês, meninas e professora, tive mais oportunidade de conhecer as outras mulheres aqui na sala e de falar assuntos que nunca tive entendimento. Foi bom, porque eu espero por igualdade e espero que o Projeto continue."

Como podemos notar na leitura dos relatos, as atuações também se tornavam um desafio, pois o público alvo, em maioria, ia à escola depois de um dia inteiro de trabalho doméstico e cuidados com os filhos. Diante disso, as extensionistas precisavam compreender e trabalhar com os diversos aspectos da rotina das mulheres participantes. Esse contato direto 
e essa troca de experiência propiciaram que formássemos vínculos, e contribuiu para bom o andamento do trabalho.

Considera-se ainda que a ação educativa enquanto expressão do cuidado em Enfermagem em Saúde Pública, entendida de forma ampliada pode ocorrer tanto em momentos formais, planejados, quanto em momentos informais como em conversas com os moradores ou durante visitas domiciliares. (ACIOLI, 2008, p.120)

Os resultados foram significativos, tornando-se assim visível a importância das ações extensionistas bem como a receptividade, participação e interesse nas oficinas promovidas.

\subsection{Contribuições}

O encaminhar do projeto proporcionou destacar que ainda há muitas lacunas e que, muitas delas, podem ser sanadas através de diálogos oferecendo uma atenção integral a saúde da mulher, valorizando os problemas esquecidos dando-lhes, assim, uma voz ativa.

O projeto torna-se enriquecedor para a formação acadêmica e pessoal, pois possibilita a visualização de déficits de ensino na abordagem desta população; a participação junto às mulheres propiciou um olhar diferenciado para o visível e invisível, tornando ampla a partilha de conhecimentos.

A atuação foi avaliada como positiva pelas participantes, pois gostaram do modo que foi abordado o tema e a maneira de interação junto a elas e, sobretudo, a oportunidade de falar e esclarecer dúvidas podendo assim, aprimorar seus conhecimentos.

Um dos itens destacados é a necessidade de respeitar uns aos outros, levando em consideração a diferença de personalidade, pois as diferenças enriqueciam o grupo, o que resultava no modo variado de atuar nas ações.

Experiências como essa, onde aborda-se problemas relevantes a nossa realidade, teoria e prática, torna-as atuantes pessoas ativas para trabalhar junto a comunidade em seu meio profissional.

\section{CONSIDERAÇÕES FINAIS}


A violência contra mulher é um grave problema que merece ser explanado, reconhecido e enfrentado, tanto pela sociedade como pelos governantes, através de políticas que exerçam a sua função de prevenir e combater.

Foi possível observar que trabalhar em um grupo onde transparece a autoestima, aceitação e direitos contribui para uma melhor qualidade de vida independente da condição em que se encontra.

A construção estereotipada de papéis é histórica e atribui à mulher, uma posição diferente perante o homem, que faz uso de diversos mecanismos para valer a sua suposta superioridade. O cuidar da saúde mental tornou-se importante para as participantes, porque as fizeram pensar que nós, temos a capacidade de fazer escolhas.

As vivências adquiridas por meio da prática educativa promovida pelo projeto são de suma importância no que se refere a nossa formação humanizada enquanto profissionais. A gama de saberes obtidos bem como a experiência de participação de uma atividade de cunho transformador na realidade da comunidade é experiências valiosas de cunho a profissional e pessoal.

\section{REFERÊNCIAS}

ACIOLI, S. A prática educativa como expressão do cuidado em Saúde Pública. Rev. bras. enferm. [online]. 2008, vol.61, n.1, pp.117-121

ANTUNES, B. O apoio matricial em saúde mental na Estratégia da Saúde da Família: concepção da equipe de apoiadores. 2015.

BRASIL, Ministério da Saúde. Saúde, migração, tráfico e violência contra mulheres: o que o SUS precisa saber: livro-texto. Universidade de Brasília. Brasília: Ministério da Saúde, 2013. Disponível em: $\underline{\text { http://bvsms.saude.gov.br/bvs/publicacoes/saude_migracao_trafico_violencia_saber.pdf. }}$ Acesso em: 30 de julho de 2017. 
BRASIL. Decreto Lei 11.340 de 7 de Agosto de 2006. Lei Maria da Penha: Coíbe a violência doméstica e familiar contra a mulher. Brasília: Secretaria Especial de Política para as Mulheres, 2008. Disponível em: http://www.planalto.gov.br/ccivil_03/_ato20042006/2006/lei/111340.htm. Acesso em: 30 de julho de 2017.

BRASIL. Ministério da Saúde. Secretaria de Atenção à Saúde. Departamento de Ações Programáticas Estratégicas. Política Nacional de Atenção Integral à Saúde da Mulher: Princípios e Diretrizes / Ministério da Saúde, Secretaria de Atenção à Saúde, Departamento de Ações Programáticas Estratégicas. - 1. ed., 2. Brasília: Editora do Ministério da Saúde, 2011. 82 p. Disponível em: http://bvsms.saude.gov.br/bvs/publicacoes/politica_nacional_mulher_principios_diretrizes.pdf . Acesso em: 30 de julho de 2017.

BRASIL. Ministério da Saúde. Secretaria de Políticas de Saúde. Violência intrafamiliar: orientações para a prática em serviço. Brasília: Ministério da Saúde, 2001. (Caderno de $\begin{array}{lllll}\text { Atenção } & \text { Básica, } & \text { ed., } & \text { Disponível }\end{array}$ http://bvsms.saude.gov.br/bvs/publicacoes/cd05_19.pdf. Acesso em: 30 de julho de 2017.

BRASIL. Ministério da Saúde. Secretaria de Vigilância em Saúde. Impacto da violência na saúde dos brasileiros / Ministério da Saúde, Secretaria de Vigilância em Saúde. - Brasília: Ministério da $\quad 2005 . \quad$ Saúde, Disponível em: http://bvsms.saude.gov.br/bvs/publicacoes/impacto_violencia.pdf. Acesso em: 30 de julho de 2017.

DE MAGALHÃES DOURADO, S; NORONHA, C. V. A face marcada: as múltiplas implicações da vitimização feminina nas relações amorosas. Physis-Revista de Saúde Coletiva, v. 24, n. 2, p. 623-643, 2014.

DE MOLINER, J; LOPES, S. M. B. Saúde mental na atenção básica: possibilidades para uma prática voltada para a ampliação e integralidade da saúde mental. Saúde e Sociedade, v. 22, n. 4, p. 1072-1083, 2013.

DUARTE, K; R. Oficinas em dinâmica de grupo com mulheres vítimas de violência doméstica: Contribuições metodológicas aos estudos sobre violência de gênero. OPSIS, Catalão, v. 1, n. 1, p. 11-124, jan./jun. 201. 
FREIRE, P. Pedagogia do oprimido. Rio de Janeiro (RJ): Paz e Terra; 1987

GOMES, I. C. R. et al. Enfrentamento de mulheres em situação de violência domestica apos agressão. Revista Baiana de Enfermagem, v. 28, n. 2, 2014.

MEINHARDT, Y. M; DA MAIA, G. F. Não é uma rede que flui-da invisibilidade às possibilidades de novos modos de cuidar: a violência contra as mulheres na saúde mental. Barbarói, n. 44, p. 120, 2015.

MINAYO M.C.S. Violência: um problema para a saúde dos brasileiros. In: Ministério da Saúde (BR), Secretaria de Vigilância em Saúde. Impacto da violência na saúde dos brasileiros. Brasília (DF); 2005. p. 9-42.

OMS, Informe Mundial sobre Violência e Saúde 2002. Disponível em: http://www.who.int/violence_injury_prevention/. Acesso em: 30 de julho de 2017.

ROSA, D. O. A. et al. A violência contra a mulher provocada por parceiro íntimo. Femina, v. 41, n. 2, 2013.

SANTOS, S. et al. Auto-organização de mulheres e saúde:relatório de atividades. 2016.

WAISELFISZ, J. J. Mapa da Violência 2015. Homicídio de mulheres no Brasil. $1^{\text {a }}$ Edição. Editora Flcsobrail. Brasília - DF - 2015. 